\title{
Effect of Selected Oligosaccharides on the Viability and Fermentation Kinetics of Lactobacillus acidophilus and Lactobacillus casei in Cultured Milk
}

\author{
Seah Young Ng, Loo Wee Chia, Birdie Scott Padam and Fook Yee Chye* \\ School of Food Science and Nutrition, Universiti Malaysia Sabah, Jalan UMS, 88400 Kota Kinabalu, Sabah, \\ Malaysia
}

\begin{abstract}
The study aimed to investigate the effect of fructo-oligosaccharides (FOS) on the growth and fermentation kinetics of Lactobacillus casei LC-01 (LC) and Lactobacillus acidophilus LA5 (LA) in cultured milk. Two commercially available FOS with different degree of polymerization (DP), namely Fibrulose F97 (DP, 2-20) and Fibruline Instant (DP, $3-60)$ were used at $4 \%(\mathrm{w} / \mathrm{v})$ and $8 \%(\mathrm{w} / \mathrm{v})$ respectively during fermentation and storage of cultured milk. Physicochemical properties and acidification kinetic of milk were measured throughout the fermentation. The concentration and DP values of the FOS do not seem to affect the growth of both probiotics during fermentation. Nevertheless, the $\mathrm{pH}$ and total soluble solid of milk fermented by both probiotics supplemented with FOS decreased tremendously during fermentation. It is noted that the percentage of lactic acid produced in $L$. acidophilus is higher than $L$. casei owing to the metabolic characteristic of the strain. The kinetic of maximum acidification rate $V_{\max }$ of cultured milk was significantly higher with the addition of FOSs at $4 \%$. However, FOS with lower DP seemed to enhance $(p<0.05)$ the stability of LA in cultured milk during cold storage, but no significant effect on LC. The results of this work indicate that FOS could significantly improve the survival of probiotics in cultured milk especially during refrigerated storage.
\end{abstract}

Keywords: Fructo-oligosaccharides, Lactobacillus acidophilus, Lactobacillus casei, growth, fermentation kinetic.

\section{INTRODUCTION}

Probiotics are defined as live microorganisms which when administered in adequate amounts confer a health benefit on the host [1]. The global probiotics market is expected to be worth US\$ 32.6 billion by 2014 , representing an annual growth of $12.6 \%$ with the Europe and Asia accounting for nearly $42 \%$ and $30 \%$ of the total revenues respectively. Dairy products, mainly yoghurts, are the most popular food carriers, and the probiotics used in these products typically are from the Lactobacillus (naturally found in the human small intestine) and Bifidobacterium (naturally found in the human large intestine) genera [2]. Their benefits to human health include prevention of diarrhea [3], reduction of cholesterol level [4], paediatric atopic dermatitis prevention [5], relief of Irritable bowel syndrome [6] and relief of milk allergy in infants [7]. In order to produce the desired benefits, probiotic bacteria should be present in the product with a minimal concentration of $10^{6}$ colony-forming units (CFU) per gram throughout the product shelf life [8]. In views of technological aspects, lactobacilli is a preferred choice to be incorporated into dairy food products as they are facultative anaerobes and tolerable to oxygen exposure during processing, transport and storage [9].

*Address correspondence to this author at the School of Food Science and Nutrition, Universiti Malaysia Sabah, Jalan UMS, 88400 Kota Kinabalu, Sabah, Malaysia; Tel: +6088-320257; Fax: +6088 320259;

E-mail: fychye@ums.edu.my
A prebiotic is a selectively fermented ingredient that allows specific changes, both in the composition and/or activity in the gastrointestinal microflora, that confer benefits upon host wellbeing and health [10]. It is expected that prebiotics improving health in a similar manner to probiotics, whilst being easier to incorporate into the diet than live microbes [11]. Oligosaccharides such as lactulose, galacto-oligosaccharides, inulin, fructo-oligosaccharides (FOS), xylo-oligosaccharide and other food carbohydrates are some of the wellknown examples of prebiotics. There is an obvious potential for a synergetic effect when combining probiotics and prebiotics appropriately, because prebiotics promote the growth and activities of probiotics [12]. Prebiotic FOSs is gaining increasing recognition as agents to modulate the colonic microbiota in humans and animals. They are relatively new functional food ingredients that have great potential as prebiotics, apart from having a number of desirable characteristics, which are beneficial to the health of consumers [13]. Some of these prebiotics selectively stimulate beneficial microbes within the gut microbiota, directly stimulate immunity, protect against pathogens, and facilitate host metabolism and mineral absorption [14].

It has been established that short-chain FOSs are fermented in the proximal colon, thereby leaving the long-chain prebiotics for more distal colonic activity [15]. A number of in vitro and in vivo studies have confirmed that inulin and long-chain FOSs are fermented into lactic and short-chain carboxylic acids 
$[16,17]$. Furthermore, it has been well demonstrated that inulin and FOS selectively stimulate the growth of bifidobacteria or lactobacilli, both of which are considered beneficial to the host [18]. Nagpal and Kaur [19] reported that addition of prebiotics has a significant effect on probiotics, and hence, a combination of suitable Lactobacillus strain(s) with a specific prebiotic could be a viable probiotic-based functional food approach in administering the beneficial bacteria invivo.

By combining the rationale of pro- and prebiotics, the concept of synbiotics is proposed referring to the potential synergy between probiotics and prebiotics [20]. The approach has been reported to enhance the efficiency through improving the growth and activities of Bifidobacterium spp. in skim milk with inulin and increase the sustainability of probiotics during cultured milk storage [21]. Up to date, studies in seeking for the appropriate match between prebiotics and probiotics for symbiosis and synbiotic effect are still ongoing. It is noticed that there is a lack of study in which the reference for fermentation kinetic with only a few attempts made using pure culture of $L$. acidophilus [22, 23, 24, 25], L. casei [26] and mixed cultures [24, 25]. Therefore, the study aimed to investigate the effect of fructo-oligosaccharides (FOS) with different degree of polymerization (DP) on the growth and fermentation kinetic of Lactobacillus casei LC-01 (LC) and Lactobacillus acidophilus LA5 (LA) in cultured milk.

\section{MATERIALS AND METHODS}

\subsection{Materials}

Lyophilized cultures of L. acidophilus LA5 (LA) and L. casei LC-01 (LC) were provided by Christian Hansen (Denmark). Chicory fructo-oligosaccharides (FOS), namely Fibrulose ${ }^{\circledR}$ F97 (DP $\left.\leq 20=92 \%\right)$ and Fibruline ${ }^{\circledR}$ Instant $(\mathrm{DP}<20=60 \%)$ supplied by Cosucra Groupe Warcoing S.A. (Belgium) were used as prebiotics [27]. Other materials used were Skim milk powder (Sunlac $^{\mathrm{TM}}$, Australia), peptone water, MRS broth and MRS agar (Merck, Malaysia).

\subsection{Fermentation of Milk}

Milk supplemented with 4\% (FI4) and 8\% (FI8) (w/v) Fibruline Instant and 4\% (FS4) (w/v) and $8 \%$ (FS8) $(w / v)$ Fibrulose F97 and non-supplemented milk (C) were submitted to the thermal treatment at $90^{\circ} \mathrm{C}$ for 5 min, followed by immediate cooling in ice water. Prior to the assay, freeze dried cultures were serially transferred 3 times in MRS broth and incubated at $37^{\circ} \mathrm{C}$ for 48 hours. The lactobacilli cells from overnight (18 hours) culture were harvested by centrifugation at $4000 \mathrm{rpm}$ for $5 \mathrm{~min}$, washed 3 times with $0.85 \% \mathrm{NaCl}$ and inoculated in the milk to obtain an initial count of 6.1-6.5 Log CFU/ml. Fermentations were conducted in the fermentor Biostat ${ }^{\circ} B$ plus (Sartorius) at $37^{\circ} \mathrm{C}$ under stirring of $60 \mathrm{rpm}$ for 60 hours [25].

\subsubsection{Enumeration of $L$. acidophilus (LA) and $L$. casei (LC)}

The viable count of $L A$ and $L C$ was determined after 12 hours up to 60 hours of fermentation. Briefly, $10 \mathrm{~g}$ of samples were withdrawn and suspended into $90 \mathrm{ml}$ of $0.1 \%(\mathrm{w} / \mathrm{v})$ peptone water followed by homogenization using stomacher. Subsequent serial dilutions were made and viable cell numbers enumerated using the pour plate technique. The counts of LA and LC were enumerated on de Mann Rogosa and Sharpe Agar (MRS, Merck) incubated anaerobically at $37^{\circ} \mathrm{C}$ for 48 72 hours. Plates containing 25-250 colonies were enumerated and recorded as colony forming unit $(\mathrm{CFU} / \mathrm{ml})$ of the sample. All samples were analyzed in triplicate; all experiments were repeated at least twice.

\subsection{2. $\mathrm{pH}$ and Lactic Acid Content}

Samples were withdrawn similarly to the method used for the determination of total viable count. The $\mathrm{pH}$ of each sample at every sampling occasion was measured using a $\mathrm{HI} 9321$ Microprocessor $\mathrm{pH}$ meter (HANNA Instruments). The $\mathrm{pH}$ meter was standardized using reference $\mathrm{pH} 4.0$ and $\mathrm{pH} 7.0$ buffer solutions. Titratable acidity (as \% lactic acid) of the cultured milk was determined in triplicate according the AOAC titration method 947.05 using $0.1 \mathrm{M} \mathrm{NaOH}$ [28].

\subsection{Storage of Fermented Milk}

Upon completion, the fermented milk was kept in sterile bottles at $4^{\circ} \mathrm{C}$ and the survival of the probiotics in the milk was enumerated as described previously.

\subsection{Kinetics of Acidification on Fermentation}

The fermentation kinetic of acidification was calculated based on the result of titratable acidity throughout the fermentation of milk, following the method described by Oliveira et al. [24]. The maximum acidification rate $\left(\mathrm{V}_{\max }\right)$ was calculated as the time variation of $\mathrm{pH}(\mathrm{dpH} / \mathrm{dt})$ and expressed as $\mathrm{pH}$ units $\min ^{-1}$. At the end of the incubation, the following kinetic parameters were also recorded: (i) $t_{\max }$, which was the time at which, $V_{\max }$ was reached; (ii) $t_{\mathrm{pH} 5.0}$, which was the time to reach $\mathrm{pH} 5.0$; and (iii) $\mathrm{t}_{\mathrm{pH} 4.5}$, which was the time to reach $\mathrm{pH} 4.5$. 


\subsection{Statistical Analysis}

Data obtained from the study were analysed using the Statistical Package of The Social Sciences (SPSS) version 17.0. Significant differences among various prebiotic formulation at different kinetic parameters were analysed by Analysis of variance (ANOVA) with mean values compared using the Tukey's test at $p<0.05$.

\section{RESULTS AND DISCUSSION}

\subsection{Enumeration of Lactobacilli During Fermentation}

The changes in $\log _{10}$ count of probiotics during milk fermentation for the first 60 hours are presented in Figure 1. Lactobacillus casei and Lactobacillus acidophilus were able to grow in skim milk and their counts were found stable after 24 hours of fermentation. FI4, FI8 and FS8 supplemented fermented milk were found to have slightly higher $L$. casei count $\left(7.7 \log _{10} \mathrm{CFU} / \mathrm{ml}\right)$ than FS4 and the control (7.4 $\left.\log _{10} \mathrm{CFU} / \mathrm{ml}\right)$ at 12 hours of fermentation; while the control had slightly higher count than all of the fructo-oligosaccharides (FOSs) added samples after 24 hours of fermentation. However, no significant different $(p>0.05)$ were observed. Similarly, after $L$. acidophilus fermented the skim milk for 12 hours, the total count of the control, FS4, FS8, FI4 and FI8 was found not significantly difference ranged between 7.4 to $7.5 \log _{10}$ $\mathrm{CFU} / \mathrm{ml}$. Significant increase of $L$. acidophilus was detected for FS4 supplemented fermentation at 24 hours. However, other formulations with FS8, FI4 and FI8 were found not significantly differed from the control, and this trend continues until the end of fermentation. These results partly concur with the study done by Rodrigues et al. [29] where they reported the insignificant growth of probiotics (Lactobacillus and Bifidobacterium) when comparing cultures in curdled milk with inulin/FOS supplementation and nonsupplemented. The significantly higher $L$. acidophilus count for FS4 at the end of fermentation shows the bifidogenic property of Fibrulose F97. Besides, Fibruline Instant also shows minor bifidogenic property during fermentation. Similar results were also reported by Moro et al. [30] who found that ingestion of prebiotics had increased the number of Lactobacilli significantly in infants. An interesting finding in the current study is that FS4 had slightly higher count (8.5 $\log _{10} \mathrm{CFU} / \mathrm{ml}$ ) than FS8 $\left(8 \log _{10} \mathrm{CFU} / \mathrm{ml}\right)$, indicating that the concentration of the inulin used has great influence on the total number of Lactobacilli. However, it has been previously reported that the growth of $L$. casei was higher in reconstituted skim milk supplemented with $1 \mathrm{~g}$ Raftiline HP than $3 \mathrm{~g}$ Raftiline HP [31]. Therefore, an optimization on the concentration of the type of prebiotics used is required when applying these into foods.

LC
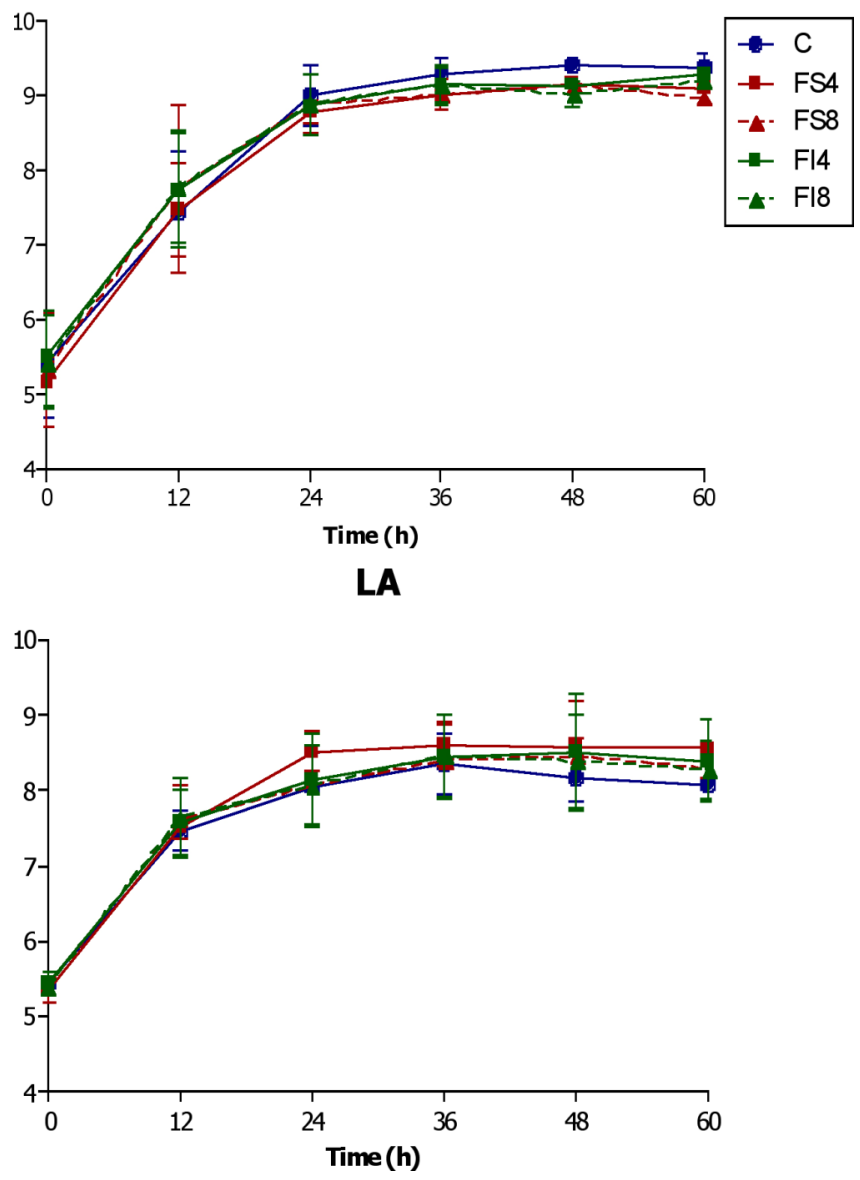

Figure 1: The extent of growth of Lactobacillus casei (LC) and Lactobacillus acidophilus (LA) for milk supplemented with various prebiotics during fermentation.

${ }^{1}$ Error bars represent standard deviations of replicates.

It is interesting to find that no significant difference $(p>0.05)$ was found in between the growth of $L$. case i in fructo-oligosaccharides supplemented or nonsupplemented milk samples (Figure 1). Although the bifidogenic nature of inulin and fructo-oligosaccharides on Lactobacillus have been reported elsewhere [32, 33], there are also contradicting reports on inulin for not supporting the growth of Lactobacillus acidophilus [31] which perhaps due to the different growth media and the sources of prebiotic used in those studies [34]. Saminathan et al. [35] further demonstrated the ability of lactobacilli to utilise FOS is strain dependent. This is probably due to lack of ability for the Lactobacillus to produce enzymes that could hydrolyse the long chain fructans such as ß-fructofuranosidase [36]. 
Nevertheless, the failure of inulin to increase the total number of $L$. casei and $L$. acidophilus could be due to the presence of other carbon source, such as sucrose in the skim milk. Barrangou et al. [37] showed that when FOS is present together with readily fermentable sugars (sucrose, glucose) even at lower concentration, the later repressed the expression of $\mathrm{msm} E$ in Lactobacillus acidophilus, which encodes a transporter associated with fructosidase. Therefore, it is suggested that the occurrence of a regulatory mechanism of preferred carbohydrate utilization pathway lowered the prebiotic effect on both probiotic strains. This further explains the reason of higher prebiotic effect of Fibrulose F97 than Fibruline Instant. It was also reported earlier that Lactobacillus selectively ferments shorter oligosaccharides than those longer chains due to the nature of low molecular mass substrates containing more non-reducing ends per unit mass that are prone to rapid attack by probiotic exo-enzymes [38, 39]. On the contrary, Aryana et al. [40] suggested that there are no growth differences between the addition of

\section{LC}

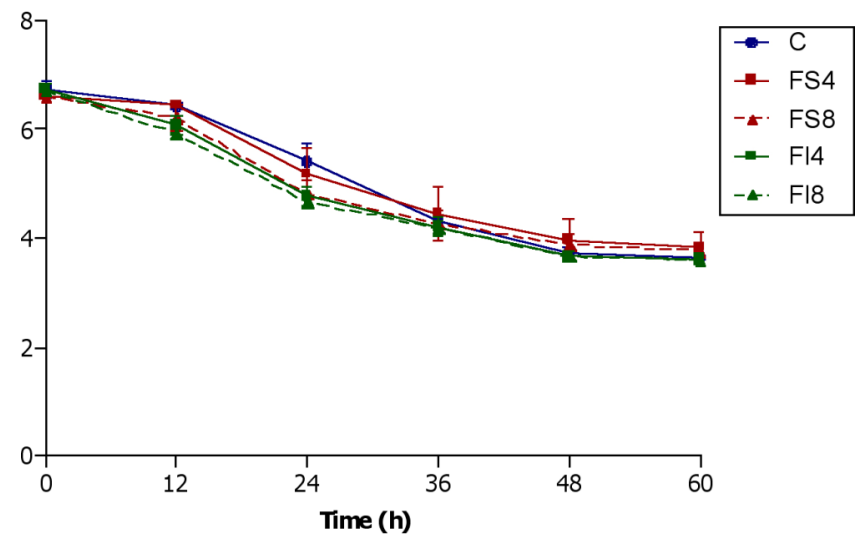

LA

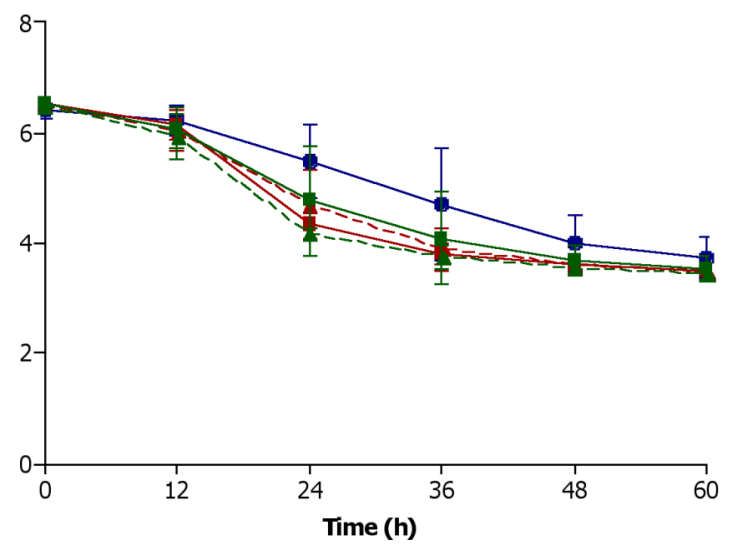

Figure 2: Changes in $\mathrm{pH}$ for milk supplemented with various prebiotics during fermentation of Lactobacillus casei (LC) and Lactobacillus acidophilus (LA).

${ }^{1}$ Error bars represent standard deviations of replicates. inulins of various chain lengths (average polymerization degree: 4, 10 and 23) into low-fat plain yoghurt. Nevertheless, the results emphasize the understanding on the mechanisms and regulation of prebiotic sugar utilization by probiotic bacteria and targeted commensals, which it is necessary for rational selection and development of effective probiotics and prebiotics cocktails.

\subsection{Changes in $\mathrm{pH}$ and Lactic Acid Production During Fermentation}

The $\mathrm{pH}$ of milk fermented by the two probiotics supplemented with various prebiotics decreased gradually from $\mathrm{pH} 6.5$ to $\mathrm{pH} 3.9$ within 60 hours of fermentation (Figure 2). Besides, the titratable acidity of fermented milk expressed in percentage of lactic acid increased from $0.1 \%$ to $0.8 \%$ and $0.9 \%$ respectively for L. casei and L. acidophilus (Figure 3 ). In addition, the current study has demonstrated a strong correlation $\left(\mathrm{R}^{2}>0.9, \mathrm{p}<0.05\right)$ between the reduction of $\mathrm{pH}$ and the production of lactic acid as the main metabolic product by the lactobacilli.

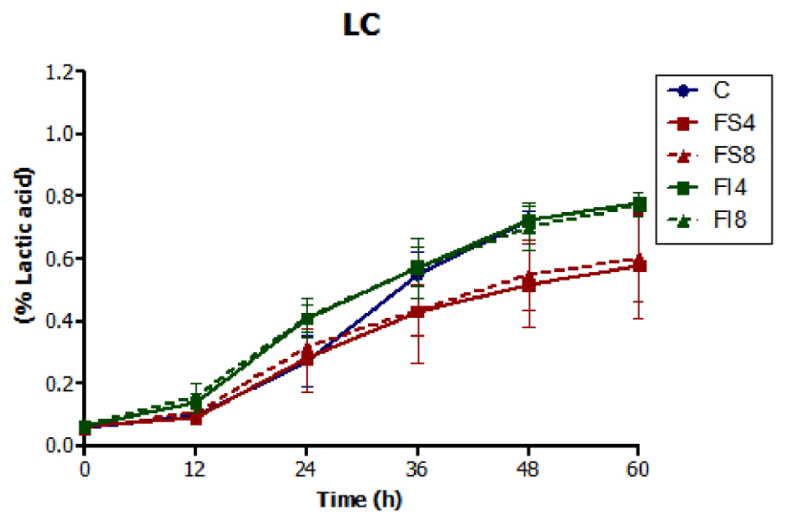

LA

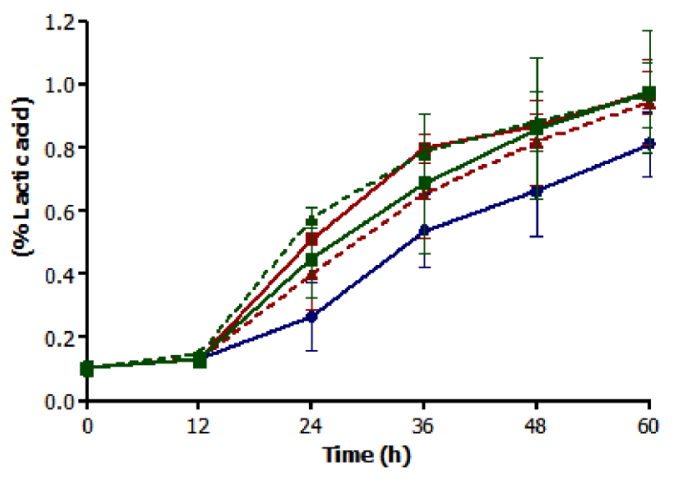

Figure 3: Production of lactic acid for milk supplemented with various prebiotics during fermentation of Lactobacillus casei (LC) and Lactobacillus acidophilus (LA).

${ }^{1}$ Error bars represent standard deviations of replicates.

For the fermentation of $L$. casei, the production of lactic acid in milk supplemented with $4 \%$ and $8 \%$ 
Fibruline Instant is significantly higher $(p<0.05)$ than the control and milk supplemented with Fibrulose F97 at 12 hours and 24 hours respectively. Meanwhile, the percentage of lactic acid produced in $L$. acidophilus fermentation showed no significant difference $(p>0.05)$ between milk supplemented with Fibruline Instant and Fibrulose F97. However, it was noticed that the acidification rate of $L$. acidophilus fermented milk was relatively faster than $L$. casei fermentation. The acidification rates had in turn influenced the availability of more favourable simple sugars such as fructose, thus increases the number of lactic acid bacteria. It was

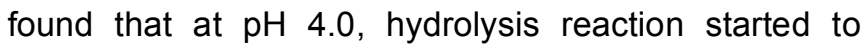
occur at the fructo-oligosaccharide chains and the stability of the chains was lowered by protonic activation of the leaving group, thus releasing more simple sugars of fructose or glucose [41]. This was further confirmed by Matusek et al. [42] where the decrease of $\mathrm{pH}$ would increase the degradation rate of the oligosaccharides. However, some of the current works exhibited contradictory results with those previously reported studies, as the addition of oligosaccharides have no effect on the rate of acidification during fermentation $[31,43]$. The variation in the acidification rate reported could be affected by the type and sources of oligosaccharides and different bacterial strains used in the study which directly affects the formation rate of different proportion of organic acids such as lactic acid, pyruvic acid and acetic acid [43]. It is also noted that the percentage of lactic acid produced by $L$. acidophilus is higher than $L$. casei owing to the homo-fermentative characteristics of the strains. L. acidophilus produces lactic acid and pyruvic acid as the main metabolites through EmbdenMeyerhoff-Parnas (EMB) pathway using NADH as the cofactor and the enzyme lactate dehydrogenase, while $L$. casei, a facultative hetero-fermentative bacterium, able to choose between utilizing EMB pathway as well as 6-phosphogluconate/phosphoketolase pathway that yields the production of other metabolites such as lactate, $\mathrm{CO}$, and ethanol which may explain the slightly lower percentage of lactic acid [44, 45, 46].

\subsection{The Effect of Prebiotic on Storage of Cultured Milk}

There were no significant differences in $\mathrm{pH}$, titratable acidity and total soluble solid between samples that were kept for one week and four weeks at refrigerated temperature (data not shown). Besides, the viability of $L$. casei was found to be stable (9.1 log $\mathrm{CFU} / \mathrm{ml}$ ) throughout the refrigerated storage (Figure 4). The result is aligned with the finding by Donkor et al. [47] who reported that lactobacilli strain, particularly $L$. casei LAFTI $^{\circledR} 26$ has good cellular stability in maintaining a constant viability throughout the storage which might have been sustained by the free amino acids in the product. It is further elaborated that the addition of prebiotic may also have sustained the metabolic activity of the probiotic organism throughout cold storage, increasing the concentration of primary metabolites but no detrimental effects caused by the high levels of lactic acid and acetic acid in the media towards the probiotic observed [48]. This phenomenon is not visualized in the cold storage of $L$. casei in the current study due to the viability of the probiotic with added prebiotic is not significant compared to ones in the control.
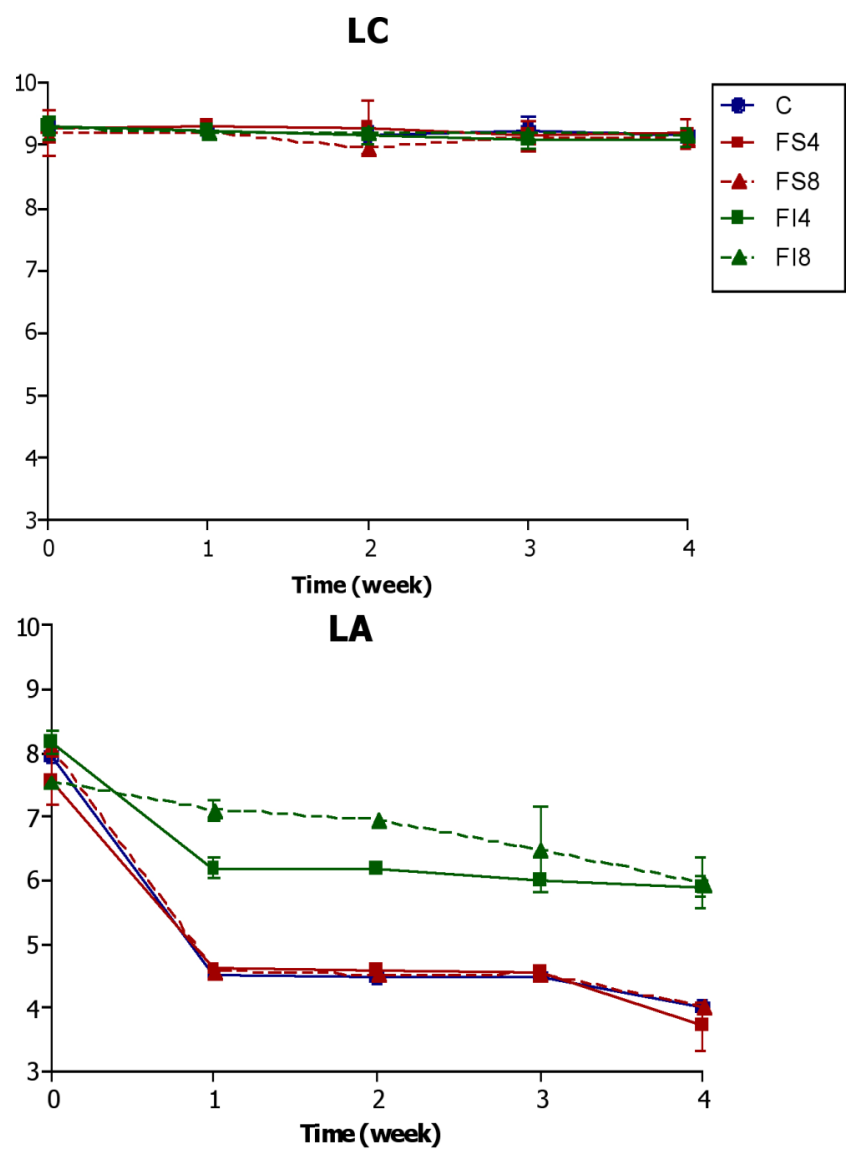

Figure 4: Survivability of Lactobacillus casei (LC) and Lactobacillus acidophilus (LA) in cultured milk during storage at $4^{\circ} \mathrm{C}$.

${ }^{1}$ Error bars represent standard deviations of replicates.

However, the viable count of $L$. acidophilus in nonsupplemented milk and milk supplemented with Fibrulose $\mathrm{F} 97$ declined by $40 \%$ from the initial $7.8 \mathrm{log}$ $\mathrm{CFU} / \mathrm{ml}$ to $4.5 \mathrm{log} \mathrm{CFU} / \mathrm{ml}$ within the first week (Figure 4). The reduction pattern of probiotic viability of FS4 and FS 8 are similar to the control for the entire 4 weeks of storage, indicating that Fibrulose F97 was not effective in protecting probiotics from the storage 
conditions. At the same time, survivability of $L$. acidophilus in milk supplemented with Fibruline Instant at both concentrations was significantly higher $(p<0.05)$ than the control throughout the four weeks of study; with FI8 showing better sustainability than FI4 at first and second week. The viable count of $L$. acidophilus in milk supplemented with Fibruline Instant is maintained at $6 \mathrm{Log} \mathrm{CFU} / \mathrm{ml}$ throughout the entire storage period from the initial count of $7 \mathrm{Log}$. The variation in viability of $L$. acidophilus is most probably due to the differences in the degree of polymerizations (DP) between Fibrulose F97 and Fibruline Instant. Fibrulose F97 was reported to contain more short chain oligosaccharides (DP<20) than Fibruline Instant [27]. The author also stated that as the degree of polymerization increased, residual FOS increased after growth of the strains, and the rate of consumption of FOS decreased. Residual FOS might function as protectant to the probiotic cells from acid injury or promote metabolic activity [49], thus sustaining the viability during low temperature storage. Besides, shorter chain fructo-oligosaccharides (Fibrulose F97) containing primarily fructose chains and fructose chain with terminal glucose bound by a (1 2) bond glycocidic linkages may have undergone rapid degradation in highly acidic environment and by $L$. acidophilus exoenzymes during fermentation could have remain in low level concentration to be able to function as protectant against acid injury due to low $\mathrm{pH}[38,40,50]$. This could be detected as a possible factor when the milk $\mathrm{pH}$ decreased rapidly during fermentation as discussed previously, because the decrease of $\mathrm{pH}$ will in turn promotes the hydrolysis reaction between bonds of fructo-oligosaccharides [42]. Besides, Hincha et al. [51] found that the fructo-oligosaccharides with higher chain length better protects cell membrane lipids. This helps to explain the reason of Fibruline Instant has better protective effect than Fibrulose F97 during low temperature storage.

\subsection{The Effect of Prebiotic on Fermentation Kinetic of Milk}

It is noted that the $V_{\max }$ value for supplemented skim milk is statistically higher than the control sample without prebiotic, particularly Fibruline Instant for both concentrations of $4 \%(\mathrm{w} / \mathrm{v})$ and $8 \%(\mathrm{w} / \mathrm{v})$ respectively. Thus, the prebiotic that showed higher acceleration of acidification is Fibrulose $\mathrm{F97}$, showing $\mathrm{V}_{\max }$ increases by $18 \%$ at $4 \%(\mathrm{w} / \mathrm{v})$ and $43 \%$ at $8 \%(\mathrm{w} / \mathrm{v})$ (Table 1$)$. In general, both of the prebiotics yielded higher $\mathrm{V}_{\max }$ value at higher concentration. Meanwhile, these two prebiotics were able to accelerate the fermentation time to achieve $\mathrm{pH} 5.0$, showing $36 \%$ time reduction for Fibrulose $\mathrm{F} 97$ at $4 \%(\mathrm{w} / \mathrm{v}), 28 \%$ for $8 \%(\mathrm{w} / \mathrm{v})$; and $39 \%$ at $8 \%(\mathrm{w} / \mathrm{v})$ Fibruline Instant. It is noted as well that, the study conducted by Oliveira et al. [52] showed higher $V_{\max }$ for $L$. casei in comparison to $L$. acidophilus with the value of $14.3 \pm 0.2$.

However, addition of prebiotics into skim milk significantly increases the time to achieve $\mathrm{V}_{\max }\left(\mathrm{t}_{\max }\right)$ and time to reach $\mathrm{pH}$ 4.5. It was also found that increase in prebiotic concentration reduced $t_{\max }$ for Fibrulose F97 but vice versa for Fibruline Instant; whilst, increase in prebiotic concentration significantly decreased $t_{\mathrm{pH} 4.5}$ for both Fibrulose F97 and Fibruline Instant. The results contradicted with the findings by Oliveira et al. [24], which showed a significant decrease in $t_{\max }$ by $5.5 \%$ in $13 \%(\mathrm{w} / \mathrm{v})$ skim milk supplemented with $4 \%(\mathrm{w} / \mathrm{v})$ oligofructose. The variation might be resulted from the use of starter culture Streptococcus thermophilus coupled with probiotic, instead of only probiotic cultures in the current study.

Table 1: Acidification kinetic parameters of fermentations of milk and milk supplemented with $4 \%$ (w/v) Fibrulose F97 (FS4), 8\% (w/v) Fibrulose F97 (FS8), 4\% (w/v) Fibruline Instant (FI4), and 8\% (w/v) Fibruline Instant (FI8), by Lactobacillus casei

\begin{tabular}{|c|c|c|c|c|}
\hline Prebiotic & $\begin{array}{c}\mathrm{V}_{\max }^{\mathrm{A}} \\
\left(10^{-3} \mathrm{pH} \text { units } / \mathrm{min}\right)\end{array}$ & $\begin{array}{l}t_{\max }{ }^{B} \\
(h)\end{array}$ & $\begin{array}{l}t_{\mathrm{pH} 5.0}{ }^{\mathrm{C}} \\
(\mathrm{h})\end{array}$ & $\begin{array}{l}t_{\mathrm{pH} 4.5}{ }^{\mathrm{c}} \\
(\mathrm{h})\end{array}$ \\
\hline Control $^{\mathrm{E}}$ & $19.03 \pm 0.03^{d}$ & $3.38 \pm 0.17^{\mathrm{a}}$ & $24.25 \pm 0.23^{c}$ & $27.67 \pm 0.25^{a}$ \\
\hline FS4 & $20.45 \pm 0.07^{d}$ & $8.38 \pm 0.18^{d}$ & $15.58 \pm 0.11^{a}$ & $33.54 \pm 0.29^{c}$ \\
\hline FS8 & $24.04 \pm 0.05^{b}$ & $4.46 \pm 0.29^{b}$ & $17.46 \pm 0.29^{b}$ & $30.50 \pm 0.35^{b}$ \\
\hline $\mathrm{Fl} 4$ & $22.40 \pm 0.85^{c}$ & $4.50 \pm 0.24^{b}$ & $24.96 \pm 0.17^{c}$ & $35.92 \pm 0.36^{d}$ \\
\hline $\mathrm{Fl8}$ & $27.13 \pm 0.16^{a}$ & $6.33 \pm 0.34^{c}$ & $14.75 \pm 0.70^{a}$ & $26.79 \pm 0.53^{a}$ \\
\hline
\end{tabular}

Means with different letters within the same column indicates significant difference $(p<0.05)$

${ }^{A}$ Maximum rate of acidification.

${ }^{\mathrm{B}}$ Time to reach $\mathrm{V}_{\max }$

${ }^{\mathrm{C}}$ Time to reach $\mathrm{pH} 5$.

Dime to reach $\mathrm{pH} 4.5$.

${ }^{\mathrm{E}}$ Not supplemented skim milk was used as the control. 


\section{CONCLUSIONS}

As conclusion, the prebiotics (FOS) were able to maintain the survival of probiotics significantly. However, the effect of fructo-oligosaccharides in maintaining the viability of Lactobacillus during storage varies with the degree of polymerization but no significant effect was observed in promoting the probiotic growth. It is suggested that longer chain prebiotics were used for maintaining the viability of probiotics especially $L$. acidophilius for long storage period. Besides, the results of kinetic parameters particularly $V_{\max }$ from this study is useful in elucidating the prebiotic effect on milk fermentation providing new insight in designing functional dairy products in the future.

\section{ACKNOWLEDGEMENT}

The authors wish to thank the Ministry of Education Malaysia and Universiti Malaysia Sabah for the financial support and postgraduate scholarship (MyBrain15). Special thanks to Sunshine Specialities Sdn. Bhd. and Cosucra, S.A, Belgium for the prebiotics used in the study.

\section{REFERENCES}

[1] FAO/WHO. Guidelines for the evaluation of probiotics in food. Food and Agriculture Organization of the United Nations and World Health Organization Working Group Report. 2002; [cited 1 September 2009]: http://www. fao.org/es/ESN/food/foodandfood_probio_en.stmS

[2] Tamime, AY, Saarela, M, Søndergaard, AK, Mistry VV, Shah, NP. Production and Maintenance of Viability of Probiotic Micro-Organisms in Dairy Products. In: Tamine, A, editor. Probiotic Dairy Products. Oxford: Blackwell Science 2007; p. 39-72.

http://dx.doi.org/10.1002/9780470995921

[3] Hickson M, D'Souza AL, Muthu N, et al. Use of probiotic Lactobacillus preparation to prevent diarrhoea associated with antibiotics: randomised double blind placebo controlled trial. Brit Med J 2007; 335: 1-5.

http://dx.doi.org/10.1136/bmj.39231.599815.55

[4] Fukushima M, Nakato M. Effects of a mixture of organisms, Lactobacillus acidophilus or Streptococcus faecalis on cholesterol metabolism in rats fed on a fat- and cholesterolenriched diet. Br J Nutr 1996; 76: 857-867. http://dx.doi.org/10.1079/BJN19960092

[5] Lee J, Seto D, Bielory L. Meta-analysis of clinical trials of probiotics for prevention and treatment of pediatric atopic dermatitis. J Allergy Clin Immunol 2008; 121: 116-121. http://dx.doi.org/10.1016/j.jaci.2007.10.043

[6] Whorwell PJ, Altringer L, Morel $\mathrm{J}$ et al. Efficacy of an encapsulated probiotic Bifidobacterium infantis 35624 in women with irritable bowel syndrome. Am J Gastroenterol 2006; 101: 1581-1590.

http://dx.doi.org/10.1111/j.1572-0241.2006.00734.x

[7] Kekkonen RA, Kajasto E, Miettinen M, Veckman V, Korpela $\mathrm{R}$, Julkunen I. Probiotic Leuconostocmesenteroides ssp. Cremoris and Streptococcus thermophilus induce IL-12 and IFN- $\gamma$ production. World J Gastroenterol 2008; 14: 11921203.

http://dx.doi.org/10.3748/wjg.14.1192
[8] Talwalkar A, Kailasapathy K. Comparison of selective and differential media for the accurate enumeration of strains of Lactobacillus acidophilus, Bifidobacterium spp. and Lactobacillus casei complex from commercial yoghurts. Int Dairy J 2004; 14: 142-149. http://dx.doi.org/10.1016/S0958-6946(03)00172-9

[9] Celik OF, O'Sullivan, DJ. Factors influencing the stability of freeze-dried stress-resilient and stress-sensitive strains of bifidobacteria. J Dairy Sci 2013; 96: 3506-3516. http://dx.doi.org/10.3168/jds.2012-6327

[10] Gibson GR. Fibre and effects on probiotics (the prebiotic concept). Clin Nutr S2004; 1: 25-31.

[11] Macfarlane S, Marfarlane GT, Cummings JH. Prebiotics: key issues. Aliment Pharmacol Ther 2006; 24:701-714. http://dx.doi.org/10.1111/j.1365-2036.2006.03042.x

[12] Ranadheera RDCS, Baines SK, Adams MC. Importance of food in probiotic efficacy. Food Res Int 2004; 43: 1-7. http://dx.doi.org/10.1016/j.foodres.2009.09.009

[13] Singh RS, Singh RP. Production of fructooligosaccharides from inulin by endoinulinases and their prebiotic potential. Food Technol Biotech 2010; 48: 435-450.

[14] Lenoir-Wijnkoop I, Sanders ME, Cabana MD et al. Probiotic and prebiotic influence beyond the intestinal tract. Nutr Rev 2007; 65: 469-489.

http://dx.doi.org/10.1111/j.1753-4887.2007.tb00272.x

[15] Kolida S, Tuohy K, Gibson GR. Prebiotic effects of inulin and oligofructose. Br J Nutr 2002; 87: 193-197. http://dx.doi.org/10.1079/BJNBJN/2002537

[16] Meyer D,Stasse-Wolthuis $M$. The bifidogenic effect of inulin and oligofructose and its consequences for gut health. Eur $\mathrm{J}$ Clin Nutr 2009; 63: 1277-1289. http://dx.doi.org/10.1038/ejcn.2009.64

[17] Roberfroid MB. Health benefits of non-digestible oligosaccharides. Adv Exp Med Biol 1997; 427: 211-219. http://dx.doi.org/10.1007/978-1-4615-5967-2 22

[18] Gourbeyre P, Denery S, Bodinier M.Probiotics, prebiotics, and synbiotics: impact on the gut immune system and allergic reactions. J Leukoc Biol 2011; 89: 685-695. http://dx.doi.org/10.1189/jlb.1109753

[19] Nagpal R, Kaur A. 2011.Synbiotic effect of various prebiotics on in vitro activities of probiotic lactobacilli. Ecol Food Nutr 2011; 50: 63-68. http://dx.doi.org/10.1080/03670244.2011.539161

[20] Gibson GR, Roberfroid MB. Dietary modulation of the colonic microbiota: Introducing the concept of prebiotics. J Nutr 1995; 125:1401-1412.

[21] Akalın AS, Fenderya S, Akbulut N. Viability and activity of bifidobacteria in yoghurt containing fructooligosaccharide during refrigerated storage. Int J Food Sci Technol 2004; 39: 613-621.

http://dx.doi.org/10.1111/j.1365-2621.2004.00829.x

[22] Ordonez GA, Fung DYC, Jeon IJ. Effect of oxyrase (TM) on the metabolic processes of lactic acid bacteria in frozen yogurt mix. J Rapid Meth Aut Mic 2000; 8: 71-81. http://dx.doi.org/10.1111/j.1745-4581.2000.tb00351.x

[23] Brizuela MA, Serrano P, Perez Y. Studies on probiotics properties of two Lactobacillus strains. Brazilian Archives of Biology and Technology 2001; 44: 95-99. http://dx.doi.org/10.1590/S1516-89132001000100013

[24] Oliveira RPS, Florance ACR, Silva RC et al. Effects of different prebiotics on the fermentation kinetics, probiotic survival and fatty acids profiles in nonfat symbiotic fermented milk. Int J Food Microbiol 2009a; 128: 467-472.

http://dx.doi.org/10.1016/j.ijfoodmicro.2008.10.012

[25] Oliveira RPS, Perego P, Converti A, Oliveira MN. Effect of inulin on growth and acidification performance of different probiotic bacteria in co-cultures and mixed culture with Streptococcus thermophilus. J Food Eng 2009b; 91: 133139.

http://dx.doi.org/10.1016/j.jfoodeng.2008.08.013 
[26] Gonzalez BA, Domınguez-Espinosa R, Alcocer BR. Aloe vera as the substrate for Lactobacillus plantarum and $L$. casei. CyTA 2008; 6: 152-157.

[27] Perrin S, Fougnies C, Grill JP, Jacobs H, Schneider F. Fermentation of chicory fructooligosaccharides in mixtures of different degrees of polymerization by three strains of bifidobacteria. Can J Microbiol 2002; 48: 759-763. http://dx.doi.org/10.1139/w02-065

[28] AOAC. Official methods of analysis.Method 947.05. Determination of acidity by titrimetric method. Washington: AOAC; 2000

[29] Rodrigues D, Rocha-Santos TAP, Pereira Cl, Gomes AM, Malcata FX, Freitas AC. The potential effect of FOS and inulin upon probiotic bacterium performance in curdled milk matrices. Food Sci Technol-LEB 2011; 44: 100-108. http://dx.doi.org/10.1016/j.Iwt.2010.05.021

[30] Moro G, Minoli I, Mosca M et al. Dosage-related bifidogenic effects of galacto and fructooligosaccharides in formula-fed term infants. J Pediatr Gastroenterol Nutr 2002; 34: 291-295. http://dx.doi.org/10.1097/00005176-200203000-00014

[31] Ramchandran L, Shah NP. Influence of addition of Raftiline HP on the growth, proteolytic, ACE- and alpha-glucosidase inhibitory activities of selected lactic acid bacteria and Bifidobacterium. Food Sci Technol 2010; 43: 146-152.

[32] Su P, Henriksson A, Mitchell H. Selected prebiotics support the growth of probiotic mono-cultures in vitro. Anaerobe 2007; 13: 134-139.

http://dx.doi.org/10.1016/j.anaerobe.2007.04.007

[33] Makras L, Van Acker G, De Vuyst L. Lactobacillus paracasei subsp. paracasei 8700:2 degrades inulin-type fructans exhibiting different degrees of polymerization. Appl and Environ Microbiol 2005; 71: 6531-6537. http://dx.doi.org/10.1128/AEM.71.11.6531-6537.2005

[34] Huebner J, Wehling RL, Hutkins RW. Functional activity of commercial prebiotics, Int Dairy J 2007; 17: 770-775. http://dx.doi.org/10.1016/j.idairyj.2006.10.006

[35] Saminathan M, Sieo CC, Kalavathy R, Abdullah N, Ho YW. Effect of prebiotic oligosaccharides on growth of Lactobacillus strains used as a probiotic for chickens. Afr $\mathrm{J}$ Microbiol Res 2011; 5: 57-64.

[36] Ryan SM, Fitzgerald GF, van Sinderen D. Transcriptional regulation and characterization of a novel $\beta$ fructofuranosidase-encoding gene from Bifidobacterium breve UCC2003. Appl Environ Microbiol 2005; 71: 34753482.

http://dx.doi.org/10.1128/AEM.71.7.3475-3482.2005

[37] Barrangou R, Altermann E, Hutkins $R$, Cano R, Klaenhammer TR. Functional and comparative genomic analyses of an operon involved in fructooligosaccharide utilization by Lactobacillus acidophilus. PNAS 2003; 100: 8957-8962.

http://dx.doi.org/10.1073/pnas.1332765100

[38] Gibson GR, Probert HM, Van Loo JAE, Rastall RA, Roberfroid MB. Dietary modulation of the human colonic microbiota: Updating the concept of prebiotics. Nutr Res Rev 2004; 17: 259-275. http://dx.doi.org/10.1079/NRR200479

[39] Goh YJ, Lee JH, Hutkins RW. Functional analysis of the fructooligosaccharide utilization operon in Lactobacillus paracasei 1195.Appl Environ Microbiol 2007; 73: 5716-5724. http://dx.doi.org/10.1128/AEM.00805-07

[40] Aryana KJ, Plauche S, Rao RM, McGrew P, Shah NP. Fatfree plain yogurt manufactured with inulins of various chain lengths and Lactobacillus acidophilus. J Food Sci2007; 72 1750-3841.

http://dx.doi.org/10.1111/j.1750-3841.2007.00302.x

[41] L'homme C, Arbelot M, Puigserver A, Biagini A. Kinetics of hydrolysis of fructooligosaccharides in mineral-buffered aqueous solutions: Influence of $\mathrm{pH}$ and temperature. J Agric Food Chem 2003; 51: 224-228. http://dx.doi.org/10.1021/jf0204699

[42] Matusek A, Merész P, Le TKD, Örsi F. Effect of temperature and $\mathrm{pH}$ on the degradation of fructo-oligosaccharides. Eur Food Res Technol 2009; 228: 355-365. http://dx.doi.org/10.1007/s00217-008-0941-8

[43] Soon, JM, MohdNordin MS, Norrakiah, AS Fructooligosaccharides in honey and effects of honey on growth of Bifidobacteriumlongum BB536. Int Food Res J 2010; 17: 557-561.

[44] Oh NS, Lee HA, Myung JH et al. Effect of different commercial oligosaccharides on the fermentation properties in kefir during fermentation. Korean J Food Sci Anim Res 2013; 33: 325-330.

http://dx.doi.org/10.5851/kosfa.2013.33.3.325

[45] Dicks LMT, Silvester M, Lawson PA, Collins MD. Lactobacillus fornicalis sp. Nov., isolated from the posterior fornix of the human vagina. Int J SystEvolMicrobiol 2000; 50: 1253-1258. http://dx.doi.org/10.1099/00207713-50-3-1253

[46] Walton GE, Swann JR, Gibson GR. Prebiotics. In: Rosenberg E, DeLong EF, Lory S, Stackebrandt E, Thompson $\mathrm{F}$, editors. The prokaryotes: human microbiology. 4th ed. Berlin: Springer 2013; p. 25-43. http://dx.doi.org/10.1007/978-3-642-30144-5 88

[47] Donkor ON, Henriksson A, Vasiljevic T, Shah NP. Effect of acidification on the activity of probiotics in yogurt during cold storage. Int Dairy J 2006; 16: 1181-1189.

http://dx.doi.org/10.1016/j.idairyj.2005.10.008

[48] Donkor ON, Nilmini SLI, Stolic P, Vasiljevic T, Shah NP. Survival and activity of selected probiotic organisms in settype yoghurt during cold storage. Int Dairy J 2007. 17: 657665.

http://dx.doi.org/10.1016/j.idairyj.2006.08.006

[49] Desai AR, Powell IB, Shah NP. Survival and activity of probiotic lactobacilli in skim milk containing prebiotics. J Food Sci2004; 69:57-60.

[50] Niness KR. Inulin and oligofructose: What are they. J Nutr 1999; 129: 1402S-1406S.

[51] Hincha DK, Zuther E, Hellwege EM, Hever AG. Specific effects of fructo- and gluco-oligosaccharides in the preservation of liposomes during drying. Glycobiology 2002; 12: $103-110$.

http://dx.doi.org/10.1093/glycob/12.2.103

[52] Oliveira RPS, Perego P, Converti A, Oliveira MN. The effect of inulin as a prebiotic on the production of probiotic fibreenriched fermented milk. Int J Dairy Technol 2009c; 62: 195203.

http://dx.doi.org/10.1111/j.1471-0307.2009.00471.x

\section{DOI: http://dx.doi.org/10.6000/1927-5951.2014.04.02.4}

(C) $2014 \mathrm{Ng}$ et al.; Licensee Lifescience Global.

This is an open access article licensed under the terms of the Creative Commons Attribution Non-Commercial License (http://creativecommons.org/licenses/by-nc/3.0/) which permits unrestricted, non-commercial use, distribution and reproduction in any medium, provided the work is properly cited. 